\title{
Modeling and Analysis of an HVAC System for the S.J. Carew Building at Memorial University
}

\author{
Almahdi Abdo-Allah \\ Department of Electrical and \\ Computer Engineering \\ Memorial University of \\ Newfoundland \\ St. John's, NL, Canada, A1B 3X5 \\ Email: atmaa7@mun.ca
}

\author{
Tariq Iqbal \\ Department of Electrical and \\ Computer Engineering \\ Memorial University of \\ Newfoundland \\ St. John's, NL, Canada, A1B 3X5 \\ Email: tariq@mun.ca
}

\author{
Kevin Pope \\ Department of Mechanical \\ Engineering \\ Memorial University of \\ Newfoundland \\ St. John's, NL, Canada, A1B 3X5 \\ Email: kpope@mun.ca
}

\begin{abstract}
In this paper, the HVAC System for the S.J. Carew Building at Memorial University is modeled using a state space multi-input and multi-output system (MIMO) approach for analyses and control system design. The IDA Indoor Climate and Energy ICE simulation program is used to develop the models. The system has three air-handling units and four floors. Supply air flow temperature and hot water temperature data are used as input data for the model. Environmental inputs of outdoor temperature, wind direction and velocity are used as disturbances. The temperature of the zones and humidity are used as output data. The simulated energy consumption for the first fifteen days of Dec 2015 is compared to measured data and good agreement is achieved for the whole building. The main purpose of this paper is to obtain a state space model of a MIMO system using the Matlab system identification toolbox. Building data and details of the model are presented in the paper.
\end{abstract}

Keywords: State space model, building modeling and simulation, HVAC, energy consumption, system identification.

\section{INTRODUCTION}

Over the past two decades, the demand for building energy has increased significantly, mainly due to economic growth in emerging markets. This has led to low fuel reserves and high pollution. To overcome these two problems, numerous studies are focusing on energy conservation and renewable energy generation [1]. For a building's heating, ventilation, and air conditioning system (HVAC), the design goal is to provide comfort to the occupants. Since the heating and cooling loads vary with time, a control system should supplement an HVAC system to maintain comfort in all conditions. Also, with proper control of the system, the energy consumption will be reduced. The HVAC system is also responsible for providing fresh outside air to the building. This paper represents a simulation of the whole building using the IDA Indoor Climate and Energy 4.7 simulation program. The performance of the detailed heating / cooling plant and energy consumption of the modelled plant consider the application of a recently developed three-dimensional model, the parameter-based heat model and standard IDA ICE model library components. The IDA Indoor Climate and Energy program is a commercial program published in May 1998 that is aimed at studying the thermal climate of individual zones [4].

\section{METHODS}

1. The case study building

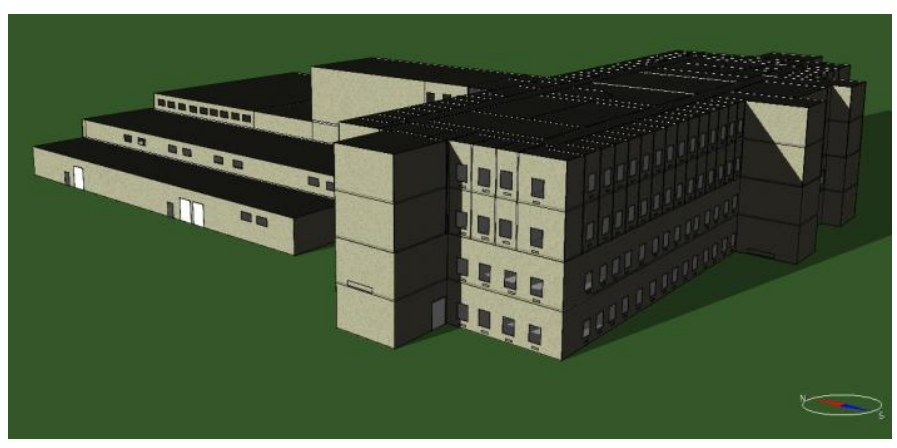

Fig. 1. 3D model of the S.J. Carew building

In this paper, the S.J. Carew Building at Memorial University's Faculty of Engineering and Applied Science is analyzed. This building consists of more than 300 zones, mainly classrooms, offices, and laboratories. Also, the building has a cafeteria. Overall, the studied building area is about $25,400 \mathrm{~m}^{2}$. The building's details are presented in Table 1 and Figure 1 shows a 3D model of the building. First, a detailed area considered with the simulation software IDA-ICE [4] model simulation is developed. This high order nonlinear model is then used as the source of the identification data and the reference model for modeling the proposed structure.

The IDA ICE program's calculations offered for most types of buildings is represented [5]:

a. The thermal balance of the area, including solar radiation, light, occupants, furniture, air leaks, heating, and cooling appliances.

b. Solar radiation from windows considering shading devices and surrounding elements.

c. Air and surface temperatures.

d. Operating temperatures. 
e. Indices of comfort: PMV, PPD and several occupants in arbitrarily chosen locations.

f. Level of daylight.

g. Humidity and $\mathrm{CO}_{2}$ levels. This provides information about the air flow system.

h. The wind and the flow caused by the buoyancy of the air through openings and leaks.

i. Airflow, $\mathrm{CO}_{2}$, pressure, and humidity in different areas of handling and distribution systems.

j. Heating power: heating and cooling units, equipment, occupants, light, solar radiation.

k. Total cost of energy using prices as a function of time.

TABLE I

DETAILS OF THE BUILDING

\begin{tabular}{|l|l|l|l|}
\hline \multicolumn{2}{|l|}{ SIMULATION TECHNOLOGY GROUP } & \multicolumn{2}{c|}{ Delivered Energy Report } \\
\hline Project & Building \\
\hline \multicolumn{2}{|l|}{} & Model floor area & $25141.7 \mathrm{~m}^{2}$ \\
\hline Customer & Model volume & $128952.9 \mathrm{~m}^{3}$ \\
\hline Created by & Almahdi Abdo-Allah & Model ground area & $10544.5 \mathrm{~m}^{2}$ \\
\hline Location & $\begin{array}{l}\text { Newfoundland (St. John's Airport) } \\
\text { _718010 (ASHRAE_ 2013) }\end{array}$ & Model envelope area & $29440.0 \mathrm{~m}^{2}$ \\
\hline Climate file & CAN_N_St.Johns.718010_CWEC & Window/Envelope & $2.4 \%$ \\
\hline Case & building2017_AHU8 & Average U-value & $0.3031 \mathrm{~W} /\left(\mathrm{m}^{2} \mathrm{~K}\right.$ ) \\
\hline Simulated & $12 / 9 / 20161: 10: 42$ AM & $\begin{array}{l}\text { Envelope area per } \\
\text { Volume }\end{array}$ & $0.2283 \mathrm{~m}^{2} / \mathrm{m}^{3}$ \\
\hline
\end{tabular}

\section{Validation of IDA ICE simulation}

It is important to determine if the model meets the specifications and that the results are correct. The hot water and electrical consumption of the building are compared with actual data that was taken from the Department of Facilities Management at Memorial University. Figure 2 shows the Honeywell software log for the hot water consumption of the building. The following output variables were measured and compared with IDA ICE simulation data:

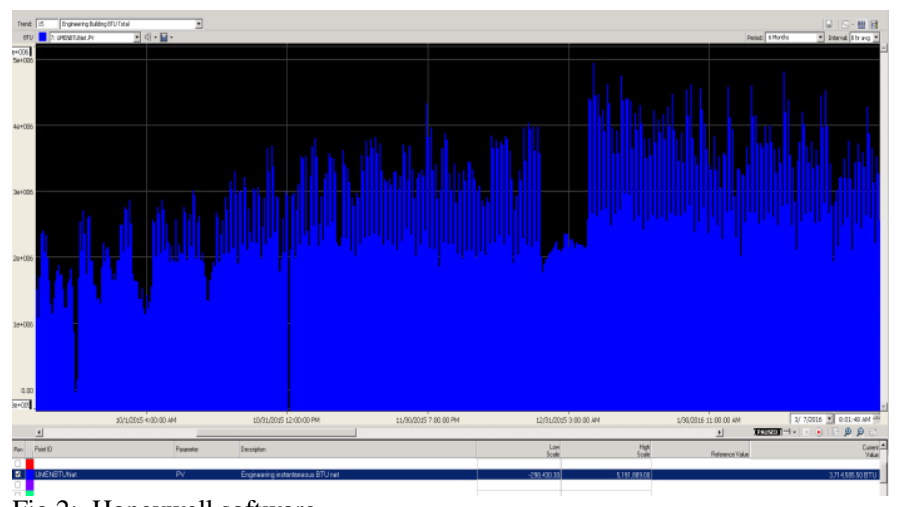

Fig 2: Honeywell software

\subsection{Outdoor temperature}

The first comparison was between the outdoor temperatures from the weather file in the IDA ICE program and data was measured from the period from the $1^{\text {st }}$ to the $18^{\text {th }}$ of Dec 2015 by one hour of simple time. This is illustrated in Figure 3.

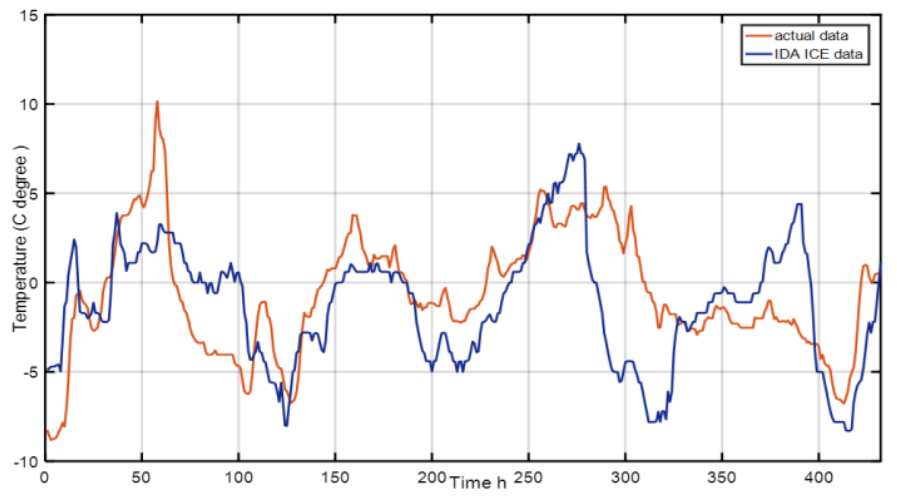

Fig. 3: Difference between outdoor temperatures of IDA ICE and actual data

\subsection{Energy consumption from hot water}

The energy consumption of hot water was 2,069.8 MBTU from IDE ICE program. However, the measured data showed 2,073 MBTU. Figure 4 shows the difference between these results for the whole Decampere 2015.

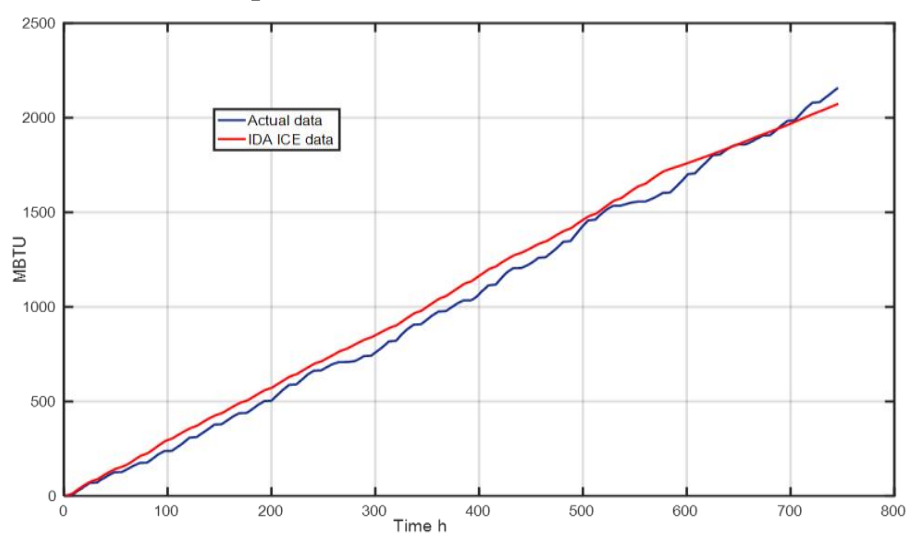

Fig. 4. Hot water consumption

\subsection{Electricity consumption}

Figure 5 shows the difference between the electrical power consumption for the measured and model data. The measured data is higher, which can likely be attributed to the many different types of laboratory equipment that the model does not represent in the analysis.

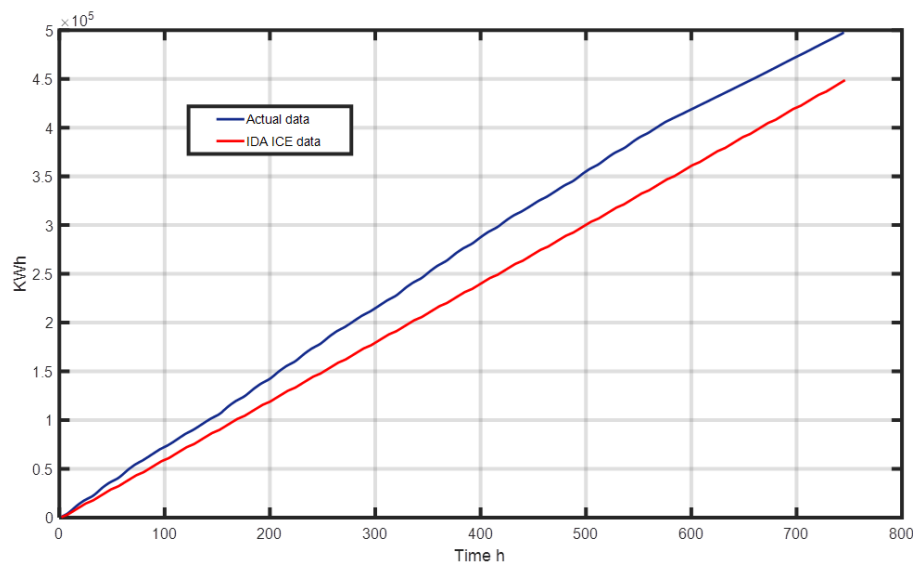

Fig. 5. Electricity consumption 


\section{SYSTEM IDENTIFICATION}

Three basic steps can be outlined when applying the system identification [2]:

i. Creation of data to be used for identification of the model.

ii. The choice of a model structure, namely a set of candidate models.

iii. Generate the model that best represents the system using a selection rule, for example, under the rule of selecting the least squares method or instrumental variables.

Precautions must be taken in each of these steps to obtain a model that can represent the real system. In this paper, the Air Handling Unit 1 (AHU1) is taken to identify the state space model of the system. Figure 6 shows details of air handling unit 1.

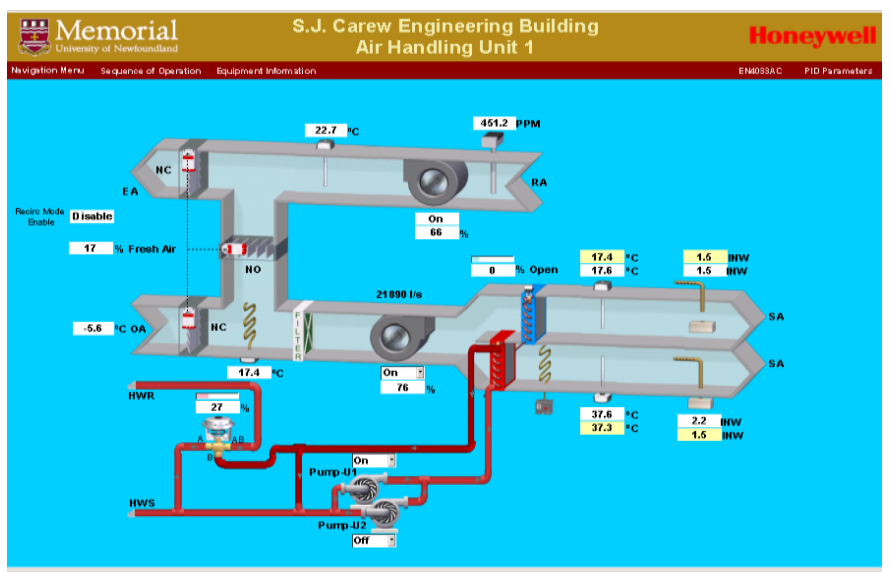

Fig. 6. Air handling unit 1.

\section{A. Choosing input signals}

It is expected that there will be an increase in the heat from radiators and air flow temperatures varying between the zone temperature and the current hot water as the minimum and maximum temperature. This is the only control variable in the zones and therefore the signals used for the identification system are input signals. Figures 7 and 8 show the supply of hot water and air flow to the system as a function of time.

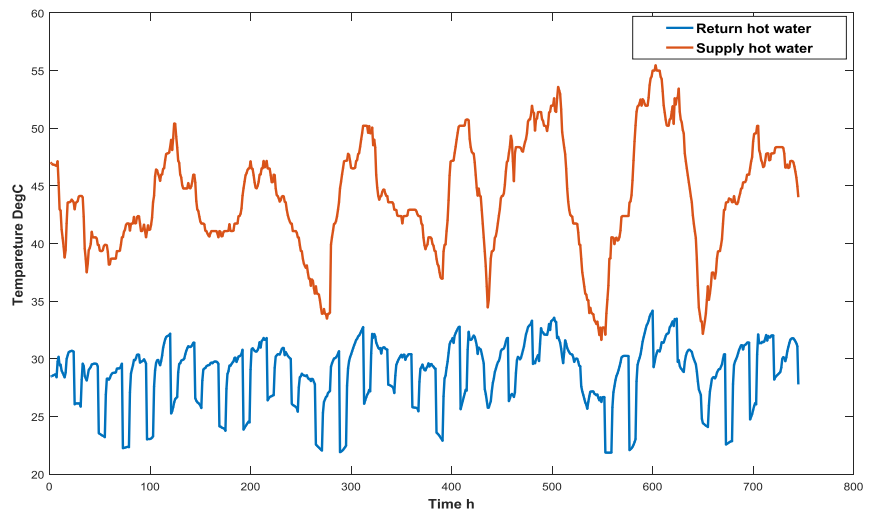

Fig. 7. Supply and return of hot water temperature.

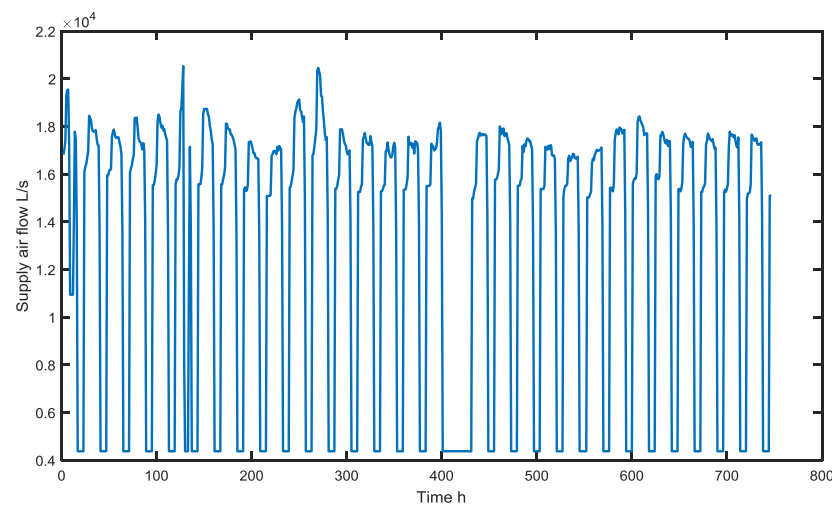

Fig. 8. Supply air flow (variation is due to damper operation)

\section{B. Choosing output signals}

The level of $\mathrm{CO}_{2}$ and the temperature of the return air flow are taken as the system outputs. Figure 9 shows $\mathrm{CO}_{2}$ level in the return air and Figure 10 shows temperature variation of the return air.

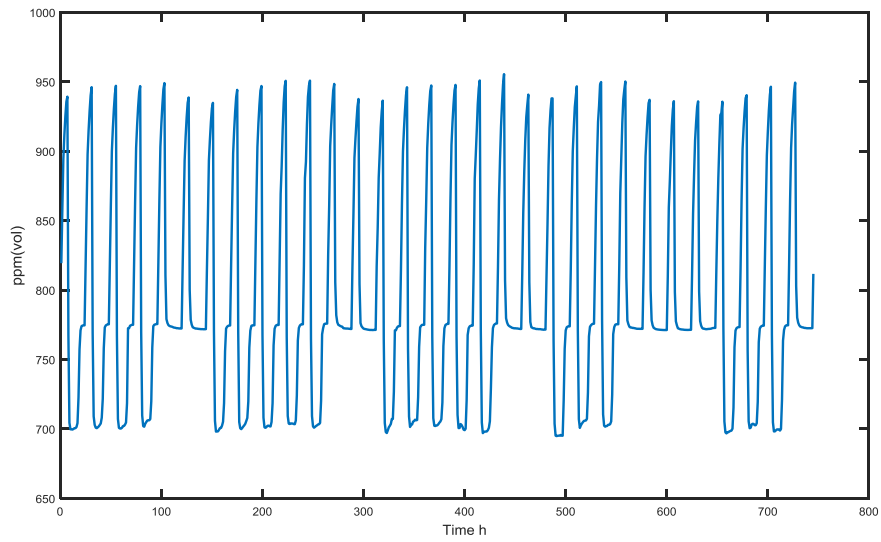

Fig. 9. Level of $\mathrm{CO}_{2}$ in the return air.

Another output is taken as the return of the hot water temperature which is shown in Figure 7.

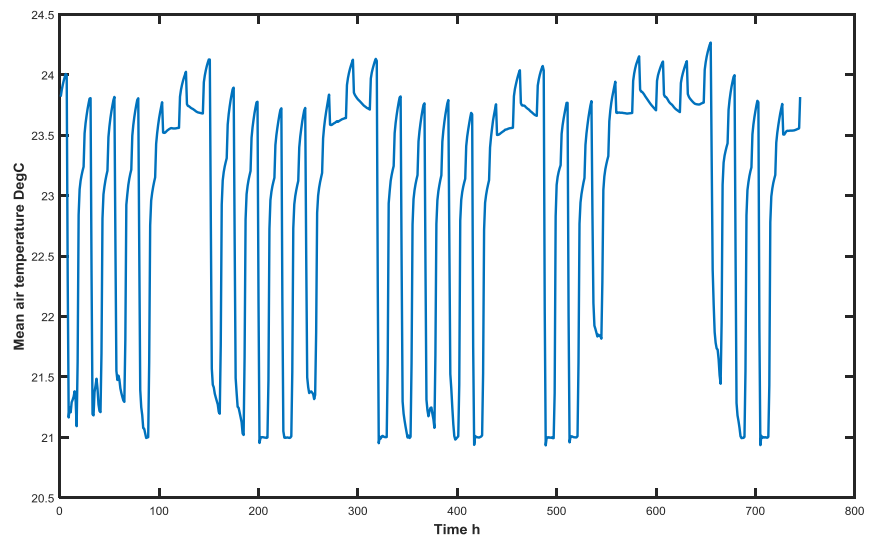

Fig. 10. Return air flow temperature

\section{Selecting a model structure}

There are several model structures that can be chosen. The model structures can be divided into two categories: linear and 
nonlinear. Since the system in this paper is nonlinear, the ARMAX-model is selected.

\section{Model identification}

In this section, the identification procedures that are considered for pre-processing the data set are presented. The procedure can be divided into the following steps [3]:

i. Choosing a model structure (e.g. ARX, ARMAX, process models).

ii. Choosing a model order.

iii. Choosing which estimation method to use (e.g. least square).

iv. Starting the identification procedure.

v. Checking and verifying the results.

\section{E. State space model}

The number of state variables, $n$, is the number of independent components of the system. The total energy of the system and the time derivatives of the state variables determine the rate of change in the energy of the system. Furthermore, the system state variables at any time, $t$, provide sufficient information to determine the values of all other variables in the system in that time [6].

$$
\begin{aligned}
& \dot{\mathbf{x}}=\mathbf{A} \mathbf{x}+\mathbf{B u} \\
& \mathbf{y}=\mathbf{C x}+\mathbf{D u} .
\end{aligned}
$$

The matrices A and B are properties of the system. The choice of output variables determines the output equation matrices $\mathrm{C}$ and $\mathrm{D}$. The following matrices are obtained using Matlab

\begin{tabular}{|c|c|c|c|c|c|c|}
\hline \multicolumn{2}{|c|}{$A=$} & & & \multicolumn{2}{|c|}{$\mathrm{B}=$} & \multirow[b]{2}{*}{ u2 } \\
\hline & $\mathrm{x} 1$ & $\mathrm{x} 2$ & $\mathrm{x} 3$ & & u1 & \\
\hline $\mathrm{x} 1$ & 0.99786 & 0.03878 & -0.0664 & $\mathrm{x} 1$ & -0.0011978 & $-3.27 \mathrm{E}-07$ \\
\hline$x 2$ & -0.1429 & 0.79996 & -0.3625 & $\mathrm{x} 2$ & -0.0049997 & $-6.01 \mathrm{E}-06$ \\
\hline $\mathrm{x} 3$ & 0.22069 & 0.51922 & 0.9535 & $\mathrm{x} 3$ & -0.0015751 & $3.58 \mathrm{E}-06$ \\
\hline \multicolumn{2}{|c|}{$\mathrm{C}=$} & & & \multicolumn{2}{|c|}{$\mathrm{D}=$} & \\
\hline & $\mathrm{x} 1$ & $x 2$ & $\mathrm{x} 3$ & & $\mathrm{u} 1$ & u2 \\
\hline y1 & -43.649 & 8.72573 & 3.5324 & y1 & 0 & 0 \\
\hline y2 & -30.577 & 8.60096 & -14.41 & y2 & 0 & 0 \\
\hline y3 & -1673.1 & 102.417 & 185.65 & y3 & 0 & 0 \\
\hline
\end{tabular}
system identification tool box.

The dynamic behavior of the system is obtained for arbitrary input and simulated by the $l \operatorname{sim}(s y s, u, t, x o)$ function in Matlab. The system has two inputs that are represented by $u$, which supply hot water and air flow to the system. In addition, the $t$ vector represents the time samples. Also, $x_{o}$ is the initial values of the system. Figure 11 shows the outputs response of the system, the mean temperature of the zones, the return hot water and the quantity of $\mathrm{CO}_{2}$.

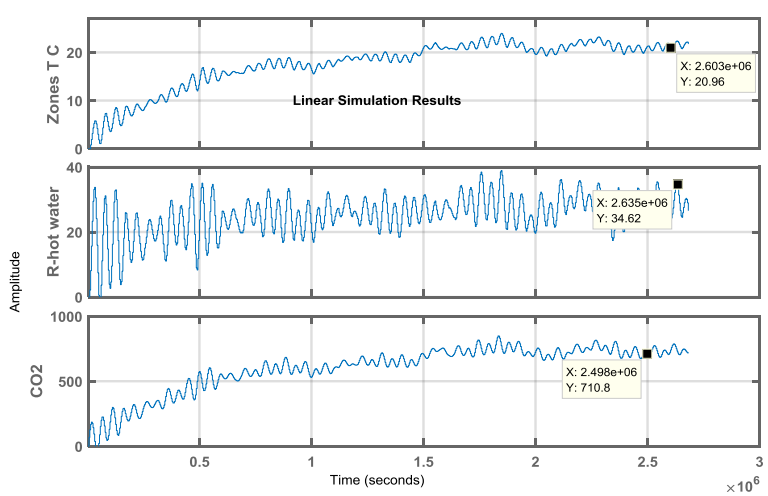

Fig. 11. Outputs of the system.

All responses of the system are in the correct range after ignoring the initial transient. Part one of Figure 11 illustrates the temperature of the zones the range between $21^{\circ} \mathrm{C}$ to $23^{\circ} \mathrm{C}$ in the steady state of the system. In part two the range of return hot water is between $20^{\circ} \mathrm{C}$ to $38^{\circ} \mathrm{C}$. In part three the level of $\mathrm{CO}_{2}$ is $700 \mathrm{ppm}$ to $850 \mathrm{ppm}$.

\section{CONCLUSION}

In this paper the S.J. Carew building with a HVAC system has been modeled using the IDA ICE program. This model provides good approximation results in which the hot water and electrical consumption are compared with measured data. In addition, the outdoor temperature for the program and measured data for a period are compared as the first step of the process. In the second step, the system identification tool box is applied to obtain the state space model of the multi-input and multi-output system. The model has three state variables, two inputs and three outputs and the responses of the model is within acceptable range.

\section{REFERENCES}

[1] American Society of Heating Refrigerating and Air-Conditioning Engineers, "2009 ashrae handbook, fundamentals" (2009).

[2] Ljung, L. "System identification" Theory for the user. Second education, Prentice Hall PTR, (2006).

[3] Alvsv_ag,Q "HVAC systems. Modeling, simulation and control for energy saving in HVAC-systems" M.S. thesis, Department of Engineering Cybernetics, Norwegian University of Science and Technology, (2011).

[4] EQUA Simulation AB, (January 2010): IDA Indoor Climate and Energy Version 4.7, [Online]. Available: http://www.equa.se/en/ida-ice.

[5] Ane, M. \& Teresa, A. "IDA simulation of indoor climate variations in a Church Validation of IDA model" M.S. thesis, Faculty of engineering and sustainable development, University of Gävle, (2011).

[6] Ljung, L. (n.d.). System identification toolbox 7, [Online]. Available:http://www.mathworks.com/help/pdf_doc/ident/ident.pdf. (Accessed Dec12, 2016). 